\title{
Racismo e preconceito contra os Avá-Guarani em Guaíra e Terra Roxa no Paraná.
}

\author{
Racismo y prejuicio en contra de los Avá-Guarani en Guaíra y Terra Roxa \\ en Paraná (Brasil).
}

\author{
Racism e prejudice against Ava-Guarani indians in Guaira and Terra \\ Roxa at Parana (Brazil).
}

\section{Rosângela Daiana dos Santos ${ }^{1}$}

\begin{abstract}
Resumo
Os casos de preconceito e racismo contra as comunidades indígenas em Guaíra e Terra Roxa no Paraná é preocupante e vem se agravando com o passar dos anos, a partir das análises feitas neste artigo trataremos das abordagens sobre o racismo, o preconceito e os casos onde os indígenas são reprimidos e excluídos da sociedade onde estão inseridos, como consequências de campanhas anti-indígenas lançadas por políticos. No decorrer deste artigo trataremos de discussões de uma reunião que ocorreu em uma comunidade indígena em Guaíra - PR em junho de 2016; contextualizaremos os processos históricos que levaram a matança dos povos indígenas, relacionando-a com acontecimentos dos últimos anos e as violações dos direitos indígenas. Na atualidade faz-se necessário a conscientização da população, dessa forma discutiremos soluções que podem ser tomadas para tentar mudar o rumo desses acontecimentos.
\end{abstract}

Palavras-chave: Preconceito; indígenas; Avá-Guarani.

\section{Resumen}

Los casos de prejuicios y racismos en contra de las comunidades indígenas en Guaíra y Terra Roxa en Paraná es preocupante y viene agravándose con el pasar de los años, a partir de los análisis hechos en este artículo trataremos los abordajes sobre el racismo, el prejuicio, los casos donde los indígenas son reprimidos y excluidos de la sociedad donde están insertados como consecuencias de las campañas anti-indígenas lanzadas por políticos. En el recorrer de este artículo trataremos de discusiones de una reunión que ocurrió en una comunidad indígena en Guaira- Paraná (Brasil) en junio de 2016; contextualizaremos los procesos históricos que llevaron a la matanza de los pueblos indígenas, relacionándola con acontecimientos de los últimos años y las violaciones de los derechos indígenas. En la actualidad se hace necesario la concientización de la población, de esa forma discutiremos soluciones que puedan ser tomadas para intentar cambiar el rumbo de esos acontecimientos.

Palabras claves: Prejuicio; indígena; Avá-Guaraní

\footnotetext{
1 Bacharel em Historia - America Latina (UNILA/2016). Graduando Historia - Licenciatura (UNILA). Bolsista em 2016 e 2017 no projeto de extensão: Memória Indígena e reparações pedagógicas na região de fronteira. Foz do Iguaçu - Paraná (BR). Email: rossantos104@gmail.com
} 


\begin{abstract}
The cases of prejudice and racism against indigenous communities in Guaira and Terra Roxa in Paraná are worrisome and have been getting worse over the years, based on the analysis made in this article, we will see approaches on racism, prejudice and cases where indigenous people are repressed, and excluded from the society where they are inserted, as a consequence of anti-indigenous campaigns launched by politicians. In the course of this article we will write about discussions of a meeting that took place in an indigenous community in Guaira - PR in June 2016, contextualizing the historical processes that led to the killing of indigenous peoples, relating it to recent events and violations of rights Indigenous peoples. Nowadays it is necessary to raise awareness of the population, in this way we will discuss solutions that can be taken to try to change the course of these events.
\end{abstract}

Key-words: Prejudice; indigenous; Avá-Guarani.

\title{
1. Introdução
}

Neste artigo analisaremos os casos de preconceitos contas as comunidades Guarani do Oeste do Paraná que são classificadas como Avá-Guarani, presentes nos municípios de Guaíra e Terra Roxa. Com ênfase na atualidade dessas comunidades e nos direitos indígenas que vêm sendo violados, com o objetivo de relatar estes casos, tentando dialogar com os processos históricos que esse grupo indígena está relacionado.

Esta pesquisa tem como principal objetivo repudiar as injúrias raciais, verificando os casos de preconceitos e racismo que os indígenas sofrem diariamente, através dos pressupostos históricos do grupo, identificando as formas de racismo, onde elas acontecem e a partir de quem. Dessa forma, faremos uma contextualização histórica dos grupos indígenas da Região Oeste do Paraná para compreender todos os conflitos que geraram os intensos casos de preconceito e racismo presentes na atualidade.

Baseando-nos nas grandes contribuições do Livro: Os Avá-Guarani no Oeste do Paraná: (Re) existência em Tekoha Guasu Guavira de 2016², onde são trabalhadas questões que envolvem os conflitos entre Ruralistas e os Povos Indígenas, trazendo abordagens com ênfase nos Avá-Guarani e a luta pela resistência pela demarcação de suas terras. Assim a análise crítica se complementa com fatos que foram evidenciados através de anos de pesquisas elaborados por diversos pesquisadores de várias áreas de pesquisa, que trabalharam

\footnotetext{
${ }^{2}$ Coordenação de Carlos Frederico Marés de Souza Filho, e organizado por Danielle de Ouro Mamed, Manuel Munhos Caleiro e Raul Cezar Bergold.
} 
diretamente com as comunidades indígenas e com documentos comprobatórios das violações de direitos indígenas.

De acordo com Manuel Munhoz Caleiro ${ }^{3}$ os processos históricos que as comunidades Guarani da região oeste do Paraná estiveram envolvidas e sofreram com o passar do tempo e para entender o quanto essa etnia sofreu e resistiu, a partir da seguinte forma: Iniciando com a "conquista” da América em 1942 e posteriormente: em 1877 a Matte Laranjeira, com a extração da erva mate e serviço escravo dos indígenas; em 1939 a criação do Parque Nacional do Iguaçu, desalojando os indígenas que habitavam neste espaço; 1940 começaram a colonização, uso de trabalho escravo dos indígenas e o processo de expropriação das terras dos indígenas para a venda de terras para colonos; 1973 a assinatura do tratado de Itaipu, e a formação do Lago para a barragem em 1982, comprometendo grande parte do território Guarani.

Tendo em vista que os direitos dos povos indígenas que se encontram na Constituição Da Republica Federativa do Brasil de 1988, que garantem aos Povos Indígenas o direito a diferença (costumes, línguas, crenças e tradições) e o direito a terra (demarcação e reconhecimento pelo Estado), e são essas atribuições que estão presentes na constituição, mas que estão sendo violados, dos quais trataremos nesse artigo principalmente referente às comunidades Avá-Guarani no Oeste do Paraná.

Os problemas relacionados aos Avá-Guarani e as violações de Direito que se intensificaram com a construção da Hidrelétrica Binacional de Itaipu na década de 1970 e início de 1980. Na atualidade são colocados dúvidas e empecilhos em relação à identidade indígena Guarani, que por ser um povo que está em constante movimentação, que é um aspecto cultural desta etnia, passaram a serem considerados "paraguaios" por grande parte dos brasileiros.

Neste artigo pretendemos observar o cotidiano das populações de Guaíra e Terra Roxa no Estado do Paraná, a relação que vem sido mantida nos últimos anos com os indígenas que vivem no mesmo espaço e analisaremos a convivência entre os munícipes e os indígenas. Observando os preconceitos que foram criados em relação aos grupos étnicos, como acontecem e os prejuízos que isso traz para as comunidades indígenas.

\footnotetext{
3 Território Guarani: Um espaço de Resistência. In: Os Avá-Guarani no Oeste do Paraná: (Re) existência em Tekoha Guasu Guavira. 2016.
} 
Dessa forma as análises surgiram após uma reunião em junho de 2016 que foi integrada por lideranças de quase todas as aldeias de Guaíra e Terra Roxa e com representantes de diferentes órgãos federais. Neste encontro tivemos acesso a uma série de reclamações que foram feitas pelos indígenas, muitas delas cruéis e desumanas, que eles vêm sofrendo por parte da população que reside nestes dois municípios.

As inúmeras reclamações que ficaram explicitas na reunião, a grande maioria muito grave, acabaram motivando o interesse de pesquisa mais aprofundada, aqui vamos relatar o que foi discutido na reunião e em seguida faremos uma análise em relação à história dos Povos Indígenas na Região Oeste do Paraná, pensando na possibilidade de reparações na estrutura das sociedades.

Em Agosto de 2017 foi lançado um relatório que trata das denuncias das violações dos Diretos humanos contra os Avá-Guarani do Oeste do Paraná, produzido pela Comissão Guarani Yvyrupa (CGY) como resultado de uma pesquisa continuada sobre as graves violações de Direitos humanos cometidas contra esta etnia, que reivindicam a demarcação da terra e princípios básicos da condição humana.

Neste relatório foram abordadas as inúmeras violências cometidas contra as quatorze comunidades indígenas Avá-Guarani de Guaíra e Terra Roxa, além dos casos de racismo, e é onde denunciam que:

Os sucessivos episódios da violência cometida contra as populações indígenas estabelecidas às margens do Rio Paraná e seus afluentes regionais está na origem da situação extremamente precária em que se encontram hoje, sofrendo pressões da sociedade envolvente para se retirarem seus últimos locais de ocupação. (Relatório\CGY, 2017, p.19120).

Este artigo serve para evidenciar como o senso comum e a falta de informação que a população brasileira tem em relação aos povos indígenas faz com que sejam alimentadas ideias equivocadas, a reprodução de preconceito e racismo. Com base em ideias erradas que nos mostra o quanto esse tema do conhecimento das culturas indígenas é desconhecido (ou ignorado) pela sociedade brasileira, que acaba sendo muito preconceituosa e desrespeitosa com os povos indígenas.

\section{Denúncias das violações de direito contra os Avá-Guarani em 2016}


Em 2016, foram elaboradas diversas reuniões nas comunidades indígenas que se encontravam em situações de risco e ameaçados em relação às violações de direitos dos Povos indígenas, esses encontros tinham como objetivo relatar os acontecimentos e abusos de direitos que vem sendo efetuadas contra as comunidades indígenas.

Através do Conselho Nacional de Direitos Humanos (CNDH), criado em 2014 a partir da Lei $\mathrm{n}^{\circ}$ 12.986, que está vinculada à Secretaria de Direitos Humanos da Presidência da Republica (SDH/PR), que tem por finalidade a promoção e a defesa dos direitos humanos, mediante ações preventivas, protetivas, reparadoras e sancionadoras das condutas e situações de ameaça ou violação deste direito. Onde o mesmo sugere a criação de comissões que buscam investigar e apoiar as populações e comunidades vulneráveis da sociedade brasileira.

Dessa forma foi criada a Comissão Permanente dos Direitos dos Povos Indígenas, dos Quilombolas, dos Povos e Comunidades Tradicionais, de Populações Afetadas por grandes Empreendimentos e dos Trabalhadores e Trabalhadoras Rurais envolvidos em Conflitos Fundiários (CP, Resolução no 13, de 03 de dezembro de 2015), que busca a reparação das violações de direito contra as distintas conformações de comunidades que na maioria das vezes se encontram em situação de risco por diversos fatores.

E a partir desta Comissão, foi formado então um Grupo de Trabalho sobre o direito dos Povos Indígenas e das comunidades Quilombolas da Região Sul, onde com seus representantes foram feitas visitas nas comunidades indígenas com o objetivo de relatar as violências cometidas pelo Estado brasileiro e pelas populações próximas as aldeias.

O objetivo do GT sobre os direitos dos Povos Indígenas é dar espaço para os indígenas relatar e denunciar as diferentes formas de violência e repressão contra suas comunidades, assim como ficou explícito no relatório elaborado pelo mesmo, em relação às comunidades Avá-Guarani da Região Oeste do Paraná:

O conjunto das denúncias destes povos expressa um quadro adverso de conflitos fundiários, violência policial e aprisionamento de lideranças, agressões e declarações publicas de conteúdo racista pronunciado por autoridades e agentes públicos, desatenção e negligência dos órgãos públicos quanto ao atendimento à saúde, direito à convivência familiar e comunitária, à educação escolar, diferenciada e bilíngue, moradia, segurança alimentar, regularização fundiária, dentre outras violações. (Relatório/CNDH, 2016, p.03). 
Esta pesquisa iniciou-se durante a atuação do projeto de extensão: Memória Indígena e reparações pedagógicas na Região de Fronteira, do Dr. Professor Clovis Antonio Brighenti, da Universidade Federal da Integração Latino Americana (UNILA), na qual fui bolsista durante o ano de 2016, e com o grupo que constituía o projeto pudemos participar de uma série de atividades que foram desenvolvidas dentro das aldeias Guarani na Região Oeste do Paraná.

Com a reunião em Guaíra no dia 01 de junho de 2016, que tinha como principal objetivo tratar de questões como violações de direitos humanos dos indígenas e da Proteção e segurança nas aldeias, promovida pelo Conselho Nacional de Direitos Humanos (CNDH), contando com a presença de representantes da Universidade de Brasília (UNB), Conselho Indigenista Missionário (CIMI), Fundação Nacional do Índio (FUNAI) e da Universidade Federal da Integração Latino Americana (UNILA). A finalidade do encontro foi citar e apontar as violações de direitos que vem ocorrendo nos últimos anos em Guaíra e Terra Roxa, para denunciar as injustiças que acontecem na atualidade por parte da população desses dois municípios, e os casos de racismo e preconceitos contra os indígenas.

O encontro foi sediado em uma aldeia em Guaíra, mas contava com a presença das demais lideranças das outras comunidades de Guaíra e Terra Roxa. Essa reunião foi fundamental para que se expusessem as questões de todas as comunidades, e dessa forma abordar as principais violações de direitos que os mesmos sofrem, aproveitando o espaço e as discussões e reclamações. Dessa forma a reunião serviu mesmo como uma forma de dar espaço para os indígenas reclamarem e relatarem os casos de injustiças que vem acontecendo diariamente nestes municípios.

Nesta reunião foram conversadas questões gerais que as diversas aldeias que habitam nos dois municípios estão sofrendo, inclusive das necessidades mais urgentes de cada comunidade, que em geral é principalmente a falta de terra, educação, saúde, etc. e reclamaram também que são tratados muito mal nos municípios, onde a população é preconceituosa e xenófoba, dessa forma:

[...] os indígenas relataram episódios de ataques, sequestro, abuso sexual, tentativas de atropelamento, linchamentos e ameaças de morte perpetrados por particulares e com a convivência e incentivo de autoridades públicas também com frequente alegação de que os indígenas seriam paraguaios e não brasileiros. (Relatório/CNDH, 2016, p.29). 
Houve um grande numero de reclamação em relação aos munícipes, onde os indígenas sofrem agressões, ameaças, espancamento, há uma rejeição muito forte dos indígenas na sociedade. Inclusive houve momentos que pessoas com um alto poder no município (que será trabalhado detalhadamente a seguir), chamaram a população a se defender dos indígenas. Campanhas de designação indígenas e anti-indígenas acabam diminuindo as possibilidades de trabalhos em empresas.

Foi citada a relação que acontecem nas escolas municipais, que integram os dois grupos sociais, onde as crianças indígenas sofrem preconceitos dos colegas e até de professores que excluem os indígenas das atividades programadas para todos, onde as crianças indígenas sofrem ameaças e são agredidas, o que chama atenção, porque a princípio a Escola seria o local onde se pratica o acolhimento, igualdade e inclusão, onde não haveria acontecer nenhum tipo de preconceito e exclusão.

É a partir deste relato que passamos a analisar a atuação da população desses dois municípios com os indígenas, e procuramos entender também qual seria a base desse racismo, onde teria nascido o preconceito, e o que podemos fazer para mudar o pensamento dessa população. Diante disto uma passagem do livro "Os Avá Guarani No Oeste do Paraná: re (existencia) em Tekoha Guasu Guavira" que faz um trabalho em relação às violações de direitos do povo Guarani e à resistência dos indígenas, onde fica visível no relato dos indígenas o preconceito que eles sofrem:

Mas na cidade, há lugares em que não podem falar em guarani, como na escola. Há paraguaios na escola, que preferem falar em guarani e por isso conversam com os indígenas. Então, os professores advertem que não podem falar em guarani, somente em português. (SOUZA FILHO, 2016, p.23).

O uso da escola de forma compartilhada, não se torna um espaço de inclusão, porque é neste local que os indígenas sofrem ainda mais preconceitos, onde são humilhados e desrespeitados. Inclusive é nas atividades da escola que deveria haver uma maior integração com os povos indígenas da cidade, principalmente com os colegas em sala de aula. Mas os indígenas só aparecem no ensino, quando é ensinado sobre o mito e folclore, e de uma forma muito sintética e genérica.

Assim poderiam ser criadas outras metodologias de ensino que abrem a possibilidade de estudar formas de integração entre os indígenas nas escolas com as crianças dos municípios de Guaíra e Terra Roxa, e levar em consideração a riqueza cultural dos Povos 
Guarani, dando prioridade para uma educação interdisciplinar, e com espaços para os indígenas desenvolverem suas línguas maternas.

Neste mesmo livro sobre a resistência dos Avá-Guarani, temos a representação de um depoimento indígena que demonstra as graves injustiças e depredações públicas que são cometidas pela população dos municípios em relação aos indígenas, principalmente contra as crianças, onde:

Os alunos são xingados. Tem um cachorro na frente da sede (da fazenda) que fica tocando na direção dos alunos. Falaram que os alunos indígenas são bicho, vagabundos, invasores. Eles já correram atrás dos alunos com moto quando eles desceram do ônibus para caminhar atrás da aldeia (LADEIRA e FARIA, 2016, p. 57).

Assim podemos notar que os casos de injúrias raciais, preconceitos e estereótipos estão presentes todos os dias nestes municípios, e os indígenas são os maiores prejudicados destas formas de injustiças. Que acontecem principalmente porque a população desconhece a cultura e a história dos povos indígenas, e dessa forma cometem atos desumanos com as populações indígenas.

Como vimos nos relatos citados pelos indígenas feitos durante a reunião, notamos que são frequentes os abusos de direitos, ameaças e repressões cometidas pela população, e ainda mais graves quando cometidas contra crianças e adolescentes, que colocam os indígenas em risco de morte. A partir destes relatos, faremos uma análise que envolve a história das comunidades Avá-Guarani na região Oeste do Paraná e as violações dos direitos indígenas empregados na atualidade.

\section{Início do preconceito até as Campanhas anti-indígenas}

Para que possamos entender melhor porque essas violações de direito vem acontecendo, partiremos para a contextualização histórica dos povos Guarani no Oeste do Paraná, as injustiças que lhes foram impostas, mostrando assim que a resistência dos indígenas não é recente e que durante séculos essa etnia procura diversas formas para resistir, assim no Oeste do Paraná:

[...] os Guarani no século XXI, depois de passarem por espanhóis e portugueses, jesuítas, bandeirantes e adelantados, obrages, marcha para o 
oeste, colonizadoras, Itaipu e até mesmo pela hostilidade atual da população não-indígena vizinha: permanece a resistência. (CALEIRO, 2016, p.17).

Com o processo de construção da Hidrelétrica de Itaipu e da colonização do Oeste do Paraná, muitos indígenas se sentiram acuados com a agressividade dos processos que estavam sendo implantada, fez com que grande parte da população Guarani fugisse para outros países e para outros estados brasileiros.

Atualmente quando os indígenas tentam voltar pros seus lugares de origem, encontram uma grande barreira da população não indígena, que os classificam como "paraguaios", por desconhecerem a dinâmica de territorialidade Guarani, que essencialmente não considera o espaço como Estados Nacionais, e sim como espaço e terra Guarani, que abrange Brasil, Argentina e Paraguai como um todo, podendo estar em qualquer um dos países sem se considerarem Nação do mesmo.

Com a colonização e a devastação da vegetação original da região, durante o século XIX e XX, começaram a desencadear muitos problemas com as comunidades indígenas na região Oeste do Paraná, com a aproximação e apropriação das terras indígenas, deixaram os indígenas totalmente desolados.

Para justificar a perca territorial dos indígenas, podemos iniciar com a extração de erva mate e madeira durante a colonização do Oeste Paranaense, foi através destes períodos que os indígenas foram utilizados como escravos. Principal motivo que fez com que os indígenas deixassem seus territórios e fugissem para outros lugares, e da mesma forma posteriormente aconteceu durante a expropriação das áreas a serem alagadas por Itaipu.

Podemos dizer que houve um encobrimento das comunidades guarani ${ }^{4}$ para justificar o processo de colonização, através da campanha Marcha para o Oeste que aconteceu durante o mandato do Presidente Getúlio Vargas (1937-1945), que incentivava a ocupação da costa Oeste do Brasil, para reafirmar a segurança Nacional.

A representação e a significação que os indígenas tiveram sobre a Marcha para o Oeste que podem ser expressadas posteriormente nas palavras de Raul Cezar Bergold, onde demonstra toda a imposição que os Guaranis sofreram com este processo, e de como são lembrados nos dias de hoje, assim podemos observar que na:

[...] perspectiva dos indígenas, a Marcha para o Oeste foi um processo acelerado de catástrofe. Espiritual e fisicamente domados, destruída a

\footnotetext{
${ }^{4}$ Artigo: Encobrimento Indígena no processo de colonização do Oeste do Paraná. 2017.
} 
natureza que os conformavam e que cultivavam, e violados etnicamente ou mesmo como cidadãos brasileiros, os guaranis encontrados pela Marcha estavam historicamente mortos, relegados ao passado, existindo como espectros de uma outra realidade sepultada pelo tempo. O espaço que lhes foi reservado é o de figurantes em lendas e memórias que engrandecem as aventuras, enaltecem a moralidade e a fé, enobrecem o trabalho e valorizam o triunfo dos colonizadores. (BERGOLD, 2016, p.189).

Precisamos entender o início dessas formas de discriminação, assim pensamos no momento que a sociedade passou a tratar as populações indígenas com desrespeito, havendo a intensificação nos casos de racismo no oeste paranaense. Há necessidade de estruturar políticas públicas para desconstruir o imaginário que a população tem em relação aos indígenas.

Entendemos que pela aproximação das comunidades indígenas para cada vez mais perto das cidades, acabou causando a proliferação da ideia de disputa por território, causando os diversos tipos de preconceitos e racismo contra os indígenas, e distanciando ainda mais as relações entre as populações e as comunidades indígenas.

De uma forma geral podemos entender que os conflitos começaram a ser praticados a partir do momento que há o regresso de muitas famílias indígenas para a região. E a permanência desses indígenas próximos às cidades e aos comércios, despertou medo nos proprietários e moradores, porque foi propagada a ideia de que os indígenas estavam voltando para roubar o espaço dos munícipes.

Para que possamos entender o contexto de ligação entre as comunidades indígenas e os municípios, o mapa a seguir mostra a localização das comunidades indígenas em Guaíra (8 aldeias) e Terra Roxa (6 aldeias) no Paraná, sendo que a aldeia Yvy Porã de Terra Roxa não consta neste mapa. A partir do mesma podemos notar que em Guaíra do lado esquerdo da imagem, há quatro comunidades indígenas sobre a cidade, justificando então a disputa por espaço e os posteriores problemas sociais que foram desencadeados desde o início destas comunidades.

Imagem 1 - Mapa da localização das aldeias Ava-Guarani em Guaíra e Terra Roxa. 


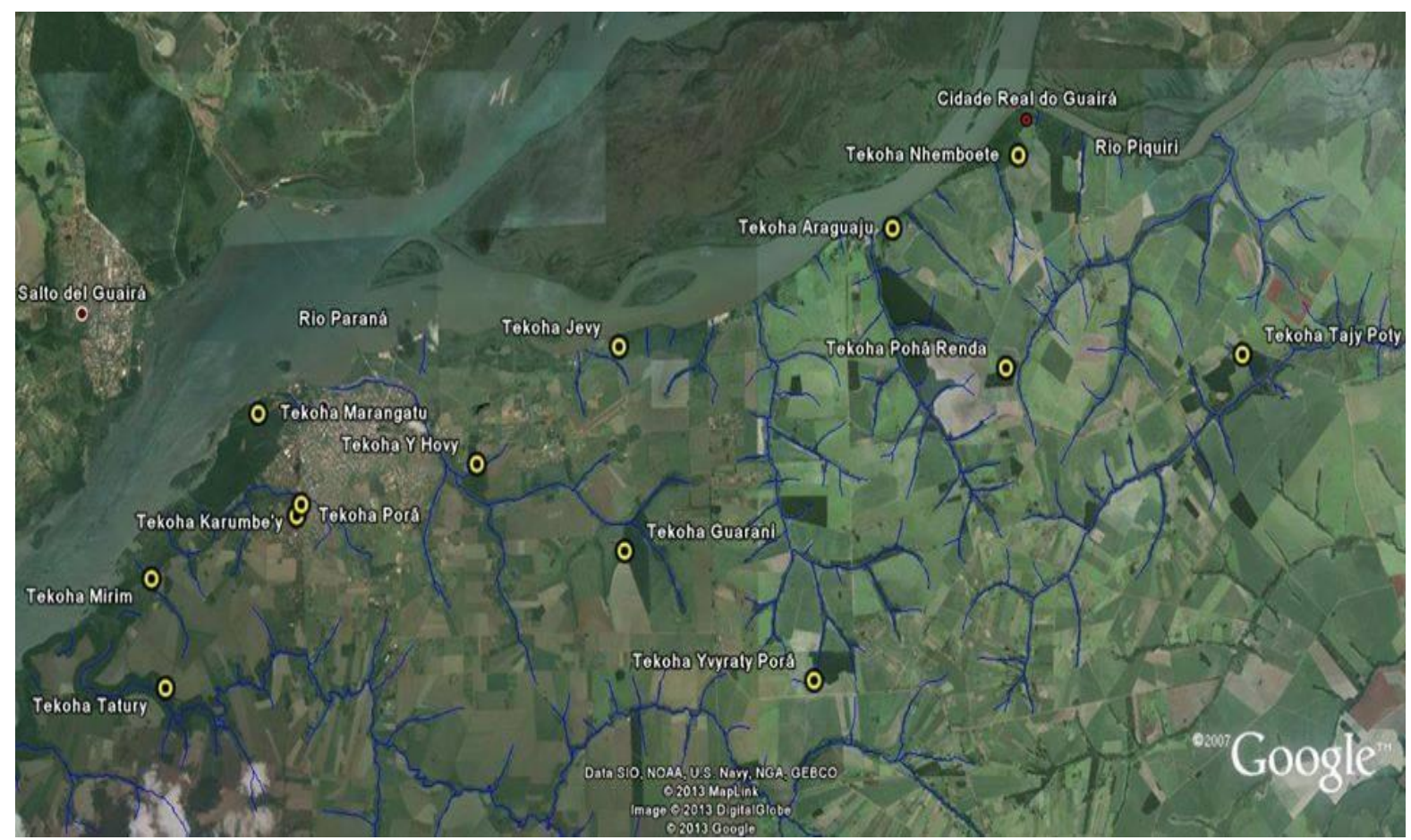

Fonte: Rede Brasil Atual. 11/07/2014

A aproximação das aldeias com as cidades é o principal motivo que leva as repressões, visto que a população se sente ameaçada com o fato dos indígenas estarem cada vez mais próximos de suas casas, propriedades e comércios. A intensificação dos casos de violências contra os indígenas são mais agravados nas cidades, dessa maneira as chamadas para a população se defender da "Invasão Indígena" era comum através de diversos meios difusores de noticias, como será analisado mais adiante.

Para analisar as violações de Direito cometidos contra os Povos indígenas usamos das palavras de Liana Amin Lima da Silva ${ }^{5}$ que destaca os direitos indígenas no âmbito das Leis que são reconhecidas pela Constituição da Republica Federativa do Brasil de 1988, e que fica definido que:

Aos povos indígenas, é assegurado o direito as terras, territórios e outros recursos, devendo essa especial relação ser respeitada, a fim de preservar as culturas e os valores espirituais e, particularmente, os aspectos coletivos dessa relação (arts. 26 e 27, da Declaração das Nações Unidas sobre os Direitos dos Povos Indígenas - ONU, 2007 - e arts. 13 e 14, da convenção n¹69 - OIT, 1989.), (SILVA, 2016, p.334).

\footnotetext{
${ }^{5}$ Justiça de transição aos Avá Guarani: A necessidade política de representações e restituição de terras pelas violações cometidas durante a Ditadura Militar. 2016.
} 
Através da Comissão Nacional da Verdade que formou um grupo de pesquisa para relatar os casos de violação de direito que ocorreram durante a Ditadura Militar (1946-1988), onde se confirmaram as denúncias das graves violações principalmente contra os povos indígenas em todo o Território Nacional. E com Comissões Estaduais da verdade que foram instauradas em todo o país, para buscar relatar detalhadamente os casos de violação de direito em casa Estado.

Dessa forma a Comissão Estadual da Verdade/PR, obteve como resultado muitas denúncias de atrocidades que foram cometidas contra as comunidades indígenas na Região Oeste do Paraná, através de relatos orais e fontes documentais que evidenciaram as violações de direito cometidas contra as comunidades indígenas durante o século XX, principalmente durante a construção da Usina Hidrelétrica de Itaipu.

E como resultado a Comissão Nacional da Verdade sugere 13 propostas de recomendações pedagógicas para que sejam feitas, para a proteção dos Povos Indígenas. Para que a partir destas denuncias e relatos, faz-se necessário o reconhecimento dos prejuízos obtidos pelas comunidades indígenas e que passam a ser feitas reparações em cada uma delas.

Podemos destacar que as comunidades indígenas que residem em Guaíra e Terra Roxa vivem em condições extremas de subsistência, não possuem saneamento básico e estão inseridos em contextos de extrema pobreza, não possuem o apoio da prefeitura, estão à margem da sociedade, assim como destacou Précoma, Nogueira e Pereira:

[...] vivem em casas improvisadas com lonas, sem coleta de lixo, sem água potável - levando-os a fazer uso de água contaminada, o que lhes causa doenças -, sem acesso a educação em língua materna. Falta-lhes emprego, alimento, e enfrentam a discriminação, sofrendo inclusive agressões psicológicas. (2016, p.401).

Dessa forma, entendemos que os conflitos gerados entre a população dos municípios e os indígenas iniciaram durante o processo de colonização do território oeste do Paraná, que comprometeu praticamente todo o território Guarani. E este conflito permanece até hoje em Guaíra, onde a cidade cresceu em torno de comunidades indígenas, e onde há reivindicações constantes de terras por parte dos indígenas, deixando os agricultores e grandes proprietários de certa forma ameaçados.

Com o processo de colonização que ocasionou na expulsão de um grande numero de indígenas, roubo de terras e os indígenas foram feitos de escravos, o que acabou colocando 
grande parte da população indígena da região em fuga e buscando refúgio nos países vizinhos. Assim como explicou Masuzaki:

Na Região Oeste do Paraná, a partir de 2012, muitos indígenas que no passado foram obrigados a se retirarem de suas terras, se refugiando em outras regiões do próprio estado paranaense, Paraguai e Mato Grosso do Sul, começam a retornar aos seus locais de origem. Nos municípios de Guaíra e Terra Roxa, conforme Oliveira (2013), o número chega a aproximadamente 1400 indígenas, em sua maioria da nação Guarani. Estando eles, organizados em treze aldeias (oito em Guaíra e cinco em Terra Roxa). (2015, p.76).

As reivindicações de espaços e demarcações de terras passaram a ser um problema para os colonos. A população se sente ameaçada com as reivindicações indígenas, e tem medo de perder suas propriedades, assim, começam a surgir inúmeras formas de ataques difamatórios contra os indígenas, e também manifestações contra a demarcação de terras, onde até os órgãos municipais se colocam ao lado dos agricultores e acabam deixando as comunidades indígenas totalmente desamparadas.

E é a partir desses acontecimentos que os casos de racismo e preconceito foram se intensificando, ganhando uma maior autonomia por influência das autoridades políticas que fizeram propagandas para produzir ainda mais discriminações contra as comunidades indígenas, assim:

[...] os Guarani são vítimas de forte preconceito e racismo das elites locais e regionais que se reproduz socialmente a partir de notícias veiculadas na imprensa. Conforme Fabrini et al (2013) os segmentos dominantes locais, apoiados inclusive por autoridades políticas, tais como deputados, prefeitos, vereadores, senadores, dentre outros, incitam ferozmente ações contra indígenas e difundem a ideia que sua existência é um prejuízo social e obstáculo ao desenvolvimento da região. (MASUZAKI, 2015, p.76)

As campanhas Anti-Indígenas eram comuns principalmente em 2012, quando as autoridades faziam uso da internet, carros de som e televisão para disseminar notícias e informações falsas em relação às comunidades indígenas, e pediam para a população ser repressiva com os índios, principalmente no comercio e nas ruas dos municípios.

As sucessivas postagens anti-indígenas nas redes sociais e sites de noticias de Guaíra e Terra Roxa fizeram com que o Ministério Público Federal em Guaíra instalasse inquéritos policiais para apurar eventuais crimes de 
RELACult - Revista Latino-Americana de Estudos em Cultura e Sociedade

Revista Latinoamericana de Estudios en Cultura y Sociedad | Latin American Journal of Studies in Culture and Society V. 03, ed. especial, dez., 2017, artigo $\mathrm{n}^{\circ}$ 587 | relacult.claec.org | e-ISSN: 2525-7870

racismo. Algumas pessoas foram denunciadas e condenadas. Como os casos correm em sigilo de justiça, não foi possível à pesquisa acessar os processos e os seus resultados. (Relatóriol CGY, 2017, p.176).

$\mathrm{Na}$ imagem a seguir é uma das formas de campanhas feitas pelo Sindicato Rural de Guaíra feitas contra as comunidades indígenas, que enfatiza as "Invasões indígenas" como algo que não combina com o progresso, elaborado e difundido por Ruralistas que usam a terra somente como valor comercial.

Imagem 2 - Campanha anti-indígena nas ruas da cidade de Guaíra-PR.

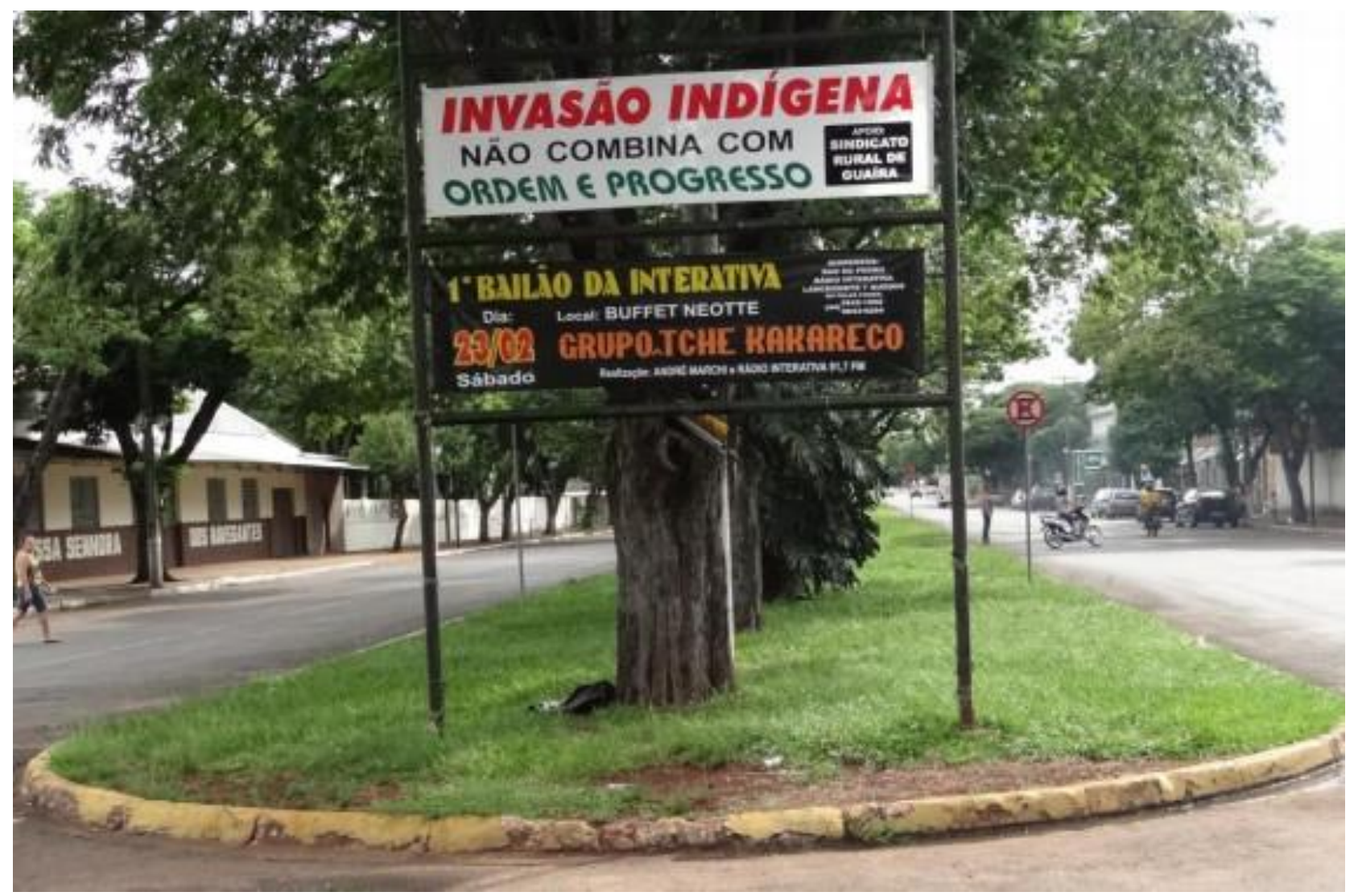

Fonte: Rede Brasil Atual. 11/07/2014

Masuzaki cita o nome de políticos que estão envolvidos nas campanhas antiindígena, e descreve como foi intensificada esta campanha, ou seja, o fortalecimento dos ruralistas com o apoio de políticos fez com que piorasse a situação dos indígenas junto à população Guaíra e Terra Roxa, agravando os casos de preconceitos e racismos dentro das cidades, no comércio, nas escolas, nas empresas que empregavam indígenas, etc.

Os Guaranis, a partir de 2012, se tornaram vítimas de uma campanha antiindígena massiva, organizada por setores ruralistas e determinados agentes públicos, como deputados, senadores e prefeitos. Reuniões foram realizadas 
em vários municípios, e contaram com a presença de figuras públicas como o Deputado Estadual pelo Paraná, Élio Lino Rusch, e o Deputado Federal Dilceu Sperafico. Os discursos proferidos nessas reuniões contribuíram para legitimar e fortalecer a disseminação do ódio e preconceito contra os indígenas. (MASUZAKI, 2015, p.80)

Assim, em relação à identidade dos povos Guarani, encontramos a explicação de Masuzaki, que demonstra o quão avassalador é pensamento da população brasileira sobre os indígenas, como ainda existe um grande desconhecimento de todos sobre os indígenas, influenciando em pensamentos racistas e xenófobos.

O grande número de ataques que os indígenas sofreram é intensificado ao longo da história, onde sua população foi praticamente toda desolada, ainda na atualidade sofrem ameaças e ataques de órgãos públicos e dos fazendeiros, e os casos de preconceito nos meios comunitários dos municípios, e que mechem com o psicológico dos indígenas.

Na luta pela sobrevivência, sem a terra demarcada, sem acesso a serviços básicos, o contexto de violências físicas e simbólica contra os guarani, acaba por corroborar o alto índice de suicídios de crianças e jovens guarani que sobre racismo nas cidades, sendo discriminadas nas escolas, chamadas de "bugres", "paraguayas", etc. (SILVA, 2016, p.351).

É muito frequente ouvir comentários de que os Guarani são Paraguaios, e esse pensamento é o resultado do desconhecimento que as pessoas tem em relação à cultura Guarani que pratica frequentes migrações. A população desses dois municípios não identificam os indígenas como Povo Guarani, mas sim como pertencentes a outros países, e enquanto fronteira com o Paraguai, são classificados dessa forma.

Silva enfatiza que os indígenas sofrem muito com essas situações que lhes foram impostas, sem muitas saídas, sem terem a quem recorrerem, aproveita para reclamar as injustiças que sofrem quando é feito o levantamento de dados sobre as violações de direitos nas aldeias, assim os indígenas:

Resistem sob a mira de ameaça de etnocídio, sofrendo massacre cotidiano orquestrado por questões de racismo, indiferença, hostilidade e repugnância da sociedade envolvente, que gera o medo e o abandono da vida (suicídios) como única alternativa para muitos jovens guaranis sem perspectivas de futuro. As famílias guarani sobreviventes, através de seus cânticos, rituais, costumes e crenças, expressam nas casas de rezas a força de Ñanderu, para seguirem lutando por seu direito à existência digna. (SILVA, 2016, p.353). 
Explica o quão importante a união e resistência dos indígenas, que mesmo estando em um espaço onde não possuem nenhuma condição de vida e não são bem vistos por praticamente toda a população está contra eles, as comunidades permanecem e se fortalecem para lutar contra todas as formas de preconceitos.

Os problemas que as comunidades Guarani sofrem são muitos e diversificados, entre eles não está apenas o preconceito que recebem da população, mas também a falta de espaço, de terras demarcadas, nenhum saneamento básico e distante de todos os direitos sociais que fazem parte da constituição nacional. Podemos dizer então, que os indígenas estão marginalizados à sociedade brasileira e que vivem na extrema pobreza.

Para compreender a interculturalidade, podemos definir como a estrutura de sociedade onde há uma formação democrática e diversamente cultural e certamente colaborativa para a integração das populações. Onde o respeito, a igualdade, a comunicação e a aprendizagem da diferença cultural são as prioridades.

De uma forma geral, tentar a convivência harmônica entre essas populações, praticando o respeito, a solidariedade, aprender a viver com a diferença do outro e respeitar o direito humano do outro, seria a melhor forma de estruturar a sociedade. Assim, o incentivo de uma relação respeitosa e aberta a conhecer a diferença do outro, se tornaria o caminho do entendimento entre essas populações.

Após as análises que foram feitas após a reunião em Guaíra em junho de 2016, vimos que os acontecimentos que envolvem os indígenas todos os dias, nas diferentes comunidades dos dois municípios citados, a população possui ideias equivocadas, pensamentos equivocados e continua reproduzindo esses mesmos pensamentos e nada está sendo feito pelos Municípios para contornar essa situação.

Podemos perceber que são pensamentos reproduzidos desde o período de ocupação da América, como explicam Ana Paula Gomes Mancini e Marta Coelho Castro Troquez, no texto "Etnocentrismo, Historia e historiografia: uma reflexão a respeito da Historia indígena no Brasil”, e fazem abordagens em relação aos estereótipos da seguinte forma:

Embora haja uma expressiva população indígena em nosso país, um aspecto a considerar são as idéias errôneas, estereotipadas e, consequentemente, preconceituosas que circulam no senso comum a respeito dos indígenas. Muitos preconceitos recorrentes no Brasil foram originados pela própria historiografia sob a influência do etnocentrismo europeu o qual marcou por 
muito tempo a historiografia ocidental e, particularmente, a brasileira (Troquez, 2005). (2009, p.185).

Mas esta questão não é tão simples, porque normalmente as pessoas apenas reproduzem o que lhes foram ensinados, tendo em vista que em muitos livros didáticos ainda são apresentadas as versões de índios nus, primitivos, rebeldes e sem diálogo. Assim como explicou Mancini e Troquez: "Cabe ressaltar que os estereótipos geradores de preconceitos construídos historicamente, muitas vezes, são reproduzidos pelos/nos próprios manuais/livros didáticos.” (2009, p.189).

Mas quanto aos livros didáticos, que já estão obtendo uma atualização positiva após a aplicação da Lei 11.645/2008, que obriga o ensino da historia e cultura indígena na educação publica e privada de todo o território Nacional. Mas ainda possuem muitos estereótipos e temas tratados de forma sintética, quando empregado nos mesmos.

Dessa maneira o que esta sendo ensinado nas escolas sobre os grupos étnicos é o principal obstáculo que temos para desconstruir as ideias equivocadas que se reproduzem na sociedade durante gerações.

Passar a pensar em projetos de inclusão dos indígenas nas escolas e em políticas públicas para adaptar as escolas para que possam receber indígenas sem deixa-los excluídos das atividades coletivas. Além de fazer preposições à prefeitura e ao governo para que sejam construídas mais escolas indígenas, para integrar as diferentes comunidades indígenas, e que dessa forma eles possam receber a educação bilíngue fazendo uso de sua língua materna.

\section{Considerações finais}

Podemos concluir que com base na reunião que foi realizada em Guaíra-PR em Junho de 2016, promovida pelo CNDH, foi de extrema importância para dar voz aos indígenas e espaço para que eles pudessem reclamar e denunciar as injustiças que sofrem todos os dias. Sendo um Órgão Nacional os resultados obtidos podem ser ainda mais gratificantes, por atingir ativistas de todo o país e inclusive abrir possibilidades para que mais pessoas possam se interessar pelas causas indígenas.

A partir desta pesquisa que demonstra os casos de violações de direitos dos povos indígenas, os problemas que foram gerados a partir de campanhas anti-indígenas e os prejuízos causados as comunidades Avá-Guarani na região Oeste do Paraná, podemos concluir que a sociedade brasileira ainda precisa aprender muito sobre a diversidade cultural 
dos povos indígenas e que não faltam oportunidades para que seja praticada a integração cultural, mas que em relação a isso não há pressa a ser feito.

A intensificação da prática de tratar as comunidades indígenas com desrespeito e preconceito que foi proliferada por Autoridades políticas, que possuem uma grande autonomia e credibilidade, tidos como exemplo, que de forma desumana colocou a população das cidades de Guaíra e Terra Roxa contra as comunidades Indígenas.

Dessa forma, concluímos que a desinformação das populações brasileiras em relação às comunidades indígenas, especialmente Guarani, faz com que sejam reproduzidas diversas formas de preconceitos e estereótipos em relação à cultura e historia deste povo. Uma sugestão de reparação para tentar finalizar com esses pensamentos seria uma capacitação ou cursos para levar a informação a essas pessoas, e principalmente tentar uma integração entre as populações e as comunidades indígenas.

Seria um grande passo se de alguma forma fosse empregada uma conscientização a população destes dois municípios, e inclusive aplicar a interculturalidade em todos os espaços, principalmente nas escolas que é onde as crianças indígenas mais sofrem preconceitos.

Praticando a articulação entre a igualdade dos direitos humanos e a diferença cultural, estruturaria uma sociedade mais justa. Dessa forma, começando pelas crianças nas escolas, com projetos de inclusão e conhecendo o diferente, poderíamos começar a ter significativas mudanças positivas na busca do término do racismo e do preconceito.

\section{Referências}

BERGOLD, Raul Cezar. O contexto, a ideologia e a pratica da Marcha para o Oeste. In: Os Avá-guarani no Oeste do Paraná: (re)existência em Tekoha Guassu Guavira. Letra da Lei, 2016.

BRIGHENTI, Clovis Antonio. SANTOS, Rosângela Daiana dos. Encobrimento Indígena no processo de colonização do oeste do Paraná. Revista SURES:

https://ojs.unila.edu.br/ojs/index.php/sures, Ano: 2017, fev, Número: 9, pág. 113-131.

CANDAU, Vera Maria. Direitos humanos, educação e interculturalidade: as tensões entre igualdade e diferença. Revista Brasileira de Educação v. 13 n. 37 jan./abr. 2008. 
CARVAlHO, Maria Lúcia Brant. Das Terras dos Índios a Índios Sem Terra, O Estado e os Guarani do Oco’y: Violência Silêncio e Luta. (Tese de doutorado em Geografia) São Paulo/SP: Universidade de São Paulo, 2013.

CNDH - CONSELHO NACIONAL DOS DIREITOS HUMANOS. Relatório do Grupo de Trabalho sobre os Direitos dos Povos Indígenas, Brasília, 2016.

Comissão Guarani Yvyrupa. Relatório sobre as violações de Direitos Humanos contra os Avá-Guarani no Oeste do Paraná. Guaíra e Terra Roxa. Agosto de 2017.

Comissão Nacional da Verdade. Relatório / Comissão Nacional da Verdade. - Brasília: CNV, 2014.

CUNHA, Manuela Carneiro. História dos índios no Brasil. São Paulo: Companhia das Letras, 1992.

DEPRÁ, Giseli. O lado de Itaipu e a luta do Avá-Guarani pela terra: representações na imprensa do Oeste do Paraná (1976-2000). Dourados: UFGD, 2006. Tese de Mestrado.

Distribuição geográfica dos treze tekohas em Guaíra e Terra Roxa. Rede Brasil Atual. 11/07/2014. Disponível em: http://www.redebrasilatual.com.br/cidadania/2014/07/guaranis-do-parana-resistem-apreconceito-enquanto-exigem-demarcacoes-na-fronteira-com-paraguai-6739.html Acessado em 28/06/2017.

FABRINI, João Edmilson et al. Conflitos entre Ruralistas, Camponeses e Indígenas no Paraná. Boletim Data Luta, Núcleo de Estudos, Pesquisas e Projetos de Reforma Agrária - NERA: Presidente Prudente, dezembro de 2013,n72.ISSN2177-446.

GREGORY,Valdir.Os eurobrasileiros e o espaço colonial: migrações no Oeste do Paraná (194070). Cascavel/PR: EDUNIOESTE, 2002.

LADEIRA, Maria Inês. FARIA, Camila Salles de. Os Avá-Guarani em YVY MBYTE, centro da Terra e processos de transformação de seu território. In: Os Avá-guarani no Oeste do Paraná: (re)existência em Tekoha Guassu Guavira. Letra da Lei, 2016.

Lei $\mathrm{n}^{\circ} 11.645 / 2008$, de 10 de março de 2008. Altera a lei $\mathrm{n}^{\circ} 9.394$, de 20 de dezembro de 1996, modificada pela Lei ${ }^{\circ} 10.639$, de 9 de janeiro de 2003, que estabelece as diretrizes e bases da educação nacional, para incluir no currículo oficial da rede de ensino a obrigatoriedade da temática "História e cultura Afro-Brasileira e indígena". Diário Oficial da União, Brasília, DF, 2008. Disponível em: http://www.planalto.gov.br/ccivil_03/_ato20072010/2008/lei/111645.htm Acessado em: 23/07/2017. 
MANCINI, Ana Paula G.; TROQUEZ, Marta C. C. Desconstruindo estereótipos: apontamentos em prol de uma prática educativa comprometida eticamente com a temática indígena. Tellus, ano 9, n. 16, jan./jun. 2009. PP. 181-206.

MASUZAKI, Teresa Itsumi. A luta dos povos Guarani no extremo oeste do Paraná. Revista Pegada - vol. 16, n. especial, maio/2015.

OLIVEIRA, Diogo de. Sobre os índios guairenses e a FUNAI. O Paranazão, 27 abril.2013.

PACKER, Ian. Violação dos direitos humanos e territoriais dos Guarani no Oeste do Paraná (1946-1988): Subsídio para a Comissão Nacional da Verdade. Centro de Trabalho Indigenista, outubro de 2013. Disponível em www.trabalhoindigenista.org.br, acessado em maio de 2017.

PRÉCOMA, Adriele Fernanda Andrade. NOGUEIRA. Caroline Barbosa Contente, PEREIRA, Elis Cristina Alves. Resistencia Avá-Guarani no Oeste do Paraná sob constante violação de direitos fundamentais. In: Os Avá-guarani no Oeste do Paraná: (re)existência em Tekoha Guassu Guavira. Letra da Lei, 2016.

PRIORI, A., et al. História do Paraná: séculos XIX e XX. Maringá: Eduem, 2012. A história do Oeste Paranaense. pp. 75-89.

SILVA, Liliana Amin Lima da. Justiça de Transição dos Avá Guarani: A necessária Política de reparações e restituição de terras pelas violações cometidas durante a ditadura militar. In: Os Avá-guarani no Oeste do Paraná: (re)existência em Tekoha Guassu Guavira. Letra da Lei, 2016.

SOUZA FILHO, Carlos Frederico Marés de. II. MAMED, Daniele de Ouro. III. CALEIRO, Manuel Munhoz. IV. BERGOLD, Raul Cezar. Os Avá-guarani no Oeste do Paraná: (re)existência em Tekoha Guassu Guavira. Letra da Lei, 2016.

TROQUEZ, Marta Coelho Castro. Etnocentrismo, História e historiografia: uma reflexão a respeito da História Indígena no Brasil. In: CONGRESSO DA SOCIEDADE DE ARQUEOLOGIA BRASILEIRA, 13, 2005, Campo Grande. Anais. Campo Grande: Sociedade Brasileira de Arqueologia, 2005. 1 CD-ROM. ISBN 85-8852-333-7. 